\title{
APLICAÇÃO DA TÉCNICA AVALIAÇÃO COOPERATIVA PARA A IDENTIFICAÇÃO DE PROBLEMAS DE USABILIDADE E FALHAS NA ARQUITETURA DA INFORMAÇÃO DO REPOSITÓRIO INSTITUCIONAL
}

\author{
Débora Koshiyama, Mestranda. \\ Programa de Pós-Graduação em Design - UFRN \\ debora@neuro.ufrn.br \\ Gabriel Marcos da Silva, Mestrando. \\ Programa de Pós-Graduação em Design - UFRN \\ gabriel.fip@gmail.com \\ André Luís Santos de Pinho, D. Sc. \\ Departamento de Estatística - UFRN \\ pinho@ccet.ufrn.br \\ José Guilherme Santa Rosa, D. Sc. \\ Programa de Pós-Graduação em Design - UFRN \\ santarosa@cchla.ufrn.br
}

RESUMO: Apresenta-se, por meio de um breve histórico, o cenário dos repositórios digitais. Analisa-se a usabilidade e a arquitetura da informação do Repositório Institucional da Universidade Federal do Rio Grande do Norte, a partir da realização da técnica Avaliação Cooperativa com um grupo de alunos de pós-graduação vinculados à referida instituição. Verifica-se que os usuários encontraram, dentre outros, problemas relacionados à terminologia, rotulagem, utilização inadequada de elementos de interface e navegação. Conclui-se que o sistema analisado não atende às necessidades e expectativas de seus usuários por apresentar problemas de usabilidade e, sobretudo, falhas na arquitetura da informação, assim como a necessidade da realização de avaliações em outros aspectos do repositório.

Palavras-chave: Design, Repositório Institucional, Usabilidade, Arquitetura da Informação, Avaliação Cooperativa.

\section{ABSTRACT:}

It is presented, through a brief history, the evolution of digital repositories. It is analyzed the usability and information architecture of the Institutional Repository of the Federal University of Rio Grande do Norte, using the Cooperative Evaluation technique with a group of graduate students. It is verified that users found, among others, issues related to terminology, labeling, improper use of interface elements and navigation. It is concluded that the analyzed system does not meet the needs and expectations of its users, presents usability problems and, above all, flaws in the information architecture. 
Keywords: Design, Institutional Repository, Usability, Information Architecture, Cooperative Evaluation.

\section{INTRODUÇÃO}

Denominamos de repositório digital a inovação tecnológica responsável pelo arquivamento eletrônico de dados que anteriormente eram armazenados fisicamente, criando um grande volume de documentos.

O repositório digital (institucional ou temático) está inserido nesse conceito, pois segundo Viana (2005), "é uma forma de armazenamento de objetos digitais que tem a capacidade de manter e gerenciar material por longos períodos de tempo e prover o acesso apropriado".

Arellano (2004, p. 17) complementa esse conceito ao afirmar que "Na preservação de documentos digitais, assim como na [preservação] dos documentos em papel, é necessária a adoção de ferramentas que protejam e garantam a sua manutenção." Assim "as condições básicas à preservação digital correspoderiam, então, a adoção desses métodos e tecnologias que integrariam a preservação física, lógica e intelectual dos objetos digitais". Além da preservação, os repositórios digitais, promovem maior visibilidade aos documentos por disponibilizá-los na Internet, permitindo, inclusive, que os mesmos tornem-se fontes de pesquisa. Destaca-se que as instituições de ensino e pesquisas vêm adotando o uso dos repositórios digitais, de acordo com Leite e Costa (2006), como uma alternativa para divulgação dos resultados científicos e acadêmicos.

\section{REPOSITÓRIO INSTITUCIONAL DA UFRN}

No ano de 2009, foi lançado o edital FINAP/PCAL/XBDB no 001/2009 , publicado pelo IBICT - Instituto Brasileiro de Informação, Ciência e Tecnologia, para apoiar as Instituições Públicas de ensino e pesquisa no país, na criação de repositórios institucionais e publicações periódicas. Para a construção dos repositórios, o IBICT exigiu a formação de uma equipe com técnico em informação (bibliotecário) e em informática, e disponibilizou a plataforma DSpace - software open source para gerenciamento de repositórios (RODRIGUES, 2014) - que permitiu a customização, por cada instituição. A Universidade Federal do Rio Grande do Norte seguiu os pontos previstos no referido Edital e no ano de 2010 implantou seu repositório institucional, vislumbrando a necessidade de preservar e ampliar a produção técnico-científica da Instituição (UNIVERSIDADE, 2014). 


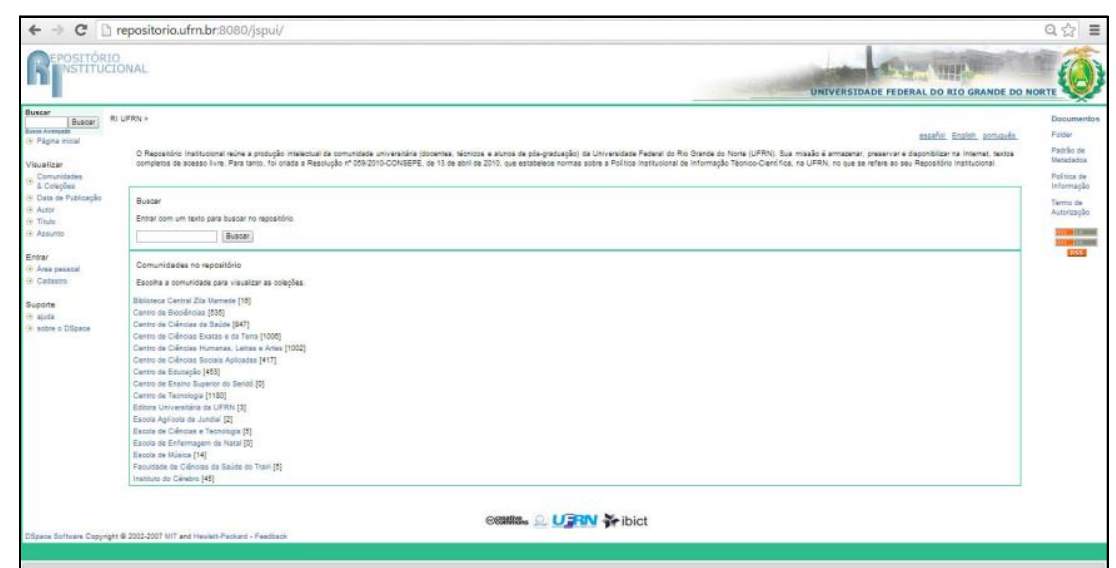

Figura 1 - Página principal do RI-UFRN

Fonte: Elaborada pelos autores, com base na pesquisa realizada.

\section{ARQUITETURA DA INFORMAÇÃO \& USABILIDADE}

Rosenfeld e Morville (2006) definem arquitetura da informação de quatro formas: a) o projeto estrutural de ambientes de informação compartilhados; b) a combinação de sistemas de organização, rotulagem, busca e navegação dentro de web sites e intranets; c) a arte e a ciência que dá forma a produtos de informação e experiências para apoio a usabilidade e facilidade de busca (findability) e; d) uma disciplina emergente e comunidade de prática focada em trazer princípios de design e arquitetura para o contexto digital. Os autores dividem, ainda, a Arquitetura da Informação de um website em quatro grandes sistemas: i) Sistema de Organização; ii) Sistema de Rotulagem; iii) Sistema de Navegação e; iv) Sistema de Busca.

De acordo com a ISO 9241, interpretada pela NBR 9241-11 (ASSOCIAÇÃO, 2002), usabilidade é a medida na qual um produto pode ser usado por usuários específicos para alcançar objetivos específicos com eficácia, eficiência e satisfação em um contexto específico de uso. Para Nielsen (1993), é importante perceber que a usabilidade não é uma propriedade única de um sistema, ela está associada a cinco atributos: 1) facilidade de aprendizagem; 2) eficiência; 3) facilidade de memorização; 4) redução de erros; 5) satisfação.

Santa Rosa e Moraes (2012a) afirmam que o objetivo de um bom design de interface é a redução do esforço cognitivo, levando o usuário a interagir melhor com o sistema. Entendendo a importância dos repositórios institucionais e percebendo que a interação com o sistema apresenta, ainda, dificuldades que poderiam estar relacionadas com a arquitetura da informação e com a usabilidade, percebeu-se a necessidade da avaliação da sua interface.

\section{MÉTODOS E TÉCNICAS}

Para identificar possíveis problemas de usabilidade e falhas na arquitetura da informação de repositórios institucionais, optou-se pelo estudo de caso do Repositório Institucional da Universidade Federal do Rio Grande do Norte. A coleta de dados foi realizada, individualmente, com 10 alunos de pós-graduação da UFRN, por meio de questionário sócio demográfico (GIL, 1999) e pelo método da avaliação cooperativa. Foram selecionadas duas tarefas representativas: 1) busca e 2) submissão de documento. 
Além do preenchimento do questionário os participantes receberam um roteiro com as tarefas a serem realizadas.

Para analisar o percurso de navegação do usuário no site, foi utilizado o software Camtasia Studio versão 8 Trial que registra áudio, vídeo e imagens das telas navegadas pelo usuário, permitindo análise detalhada da navegação. Pela ferramenta foi possível analisar os reais problemas apontados pelos usuários.

\section{RESULTADOS}

\subsection{RESULTADOS DO FORMULÁRIO SÓCIO DEMOGRÁFICO}

A partir do formulário sócio demográfico identificamos que, dos usuários envolvidos, $50 \%$ são do sexo feminino e $50 \%$ do sexo masculino; $60 \%$ estão na faixa etária de 21 a 30 anos, 20\% de 31 a 40 anos e 20\% de 41 a 50 anos; 10\% são alunos da modalidade Lato Sensu (Especialização), 70\% Stricto Sensu (Mestrado) e 20\% Stricto Sensu (Doutorado); 40\% estão ligados a curso da área de Ciências Sociais e Humanas, 30\% das Ciências Tecnológicas e 30\% das Ciências Biológicas; 60\% declararam ter pouco conhecimento da língua inglesa, $10 \%$ não tem conhecimento e $30 \%$ declararamse fluentes. Apenas um (10\%) dos participantes respondeu que já havia utilizado o repositório, com a finalidade de pesquisa, fazendo o uso por meio de notebook e que tem pouca experiência no sistema, pois utiliza há três meses, no máximo, uma vez por semana.

\subsection{RESULTADOS DA AVALIAÇÃO COOPERATIVA}

\subsubsection{Tarefa 1: busca de um documento}

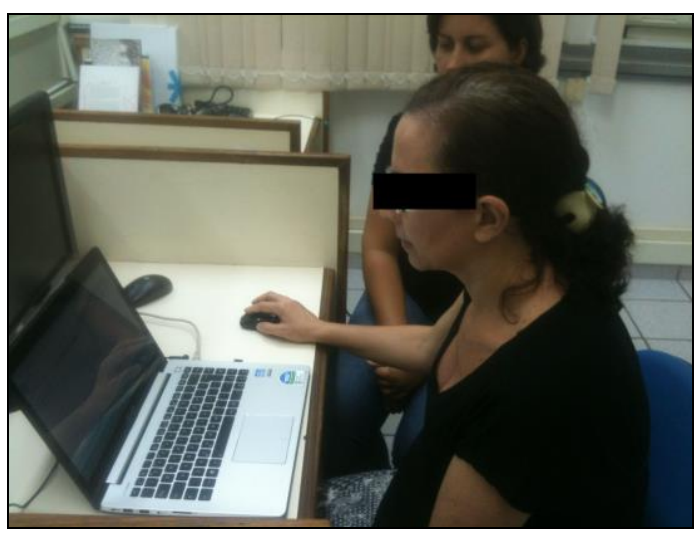

Figura 2 - Avaliação Cooperativa do RI-UFRN.

Fonte: Elaborada pelos autores, com base na pesquisa realizada.

Os principais pontos observados pelos usuários a cerca da página principal (Figura 3) e campos de busca foram: a) tamanho da fonte e caixas de busca pequenos; b) o campo de busca da barra lateral não foi percebido; c) concentrar as opções de busca em um único campo na tela principal; d) falta de padronização do texto (maiúsculas e minúsculas) e; f) interface com mais imagens e menos informação em texto. 


\section{Voz do Usuário:}

"Eu acho que se você não tem cuidado com a formatação do texto [maiúsculas e minúsculas], não me dá confiança para depositar meus documentos no repositório".

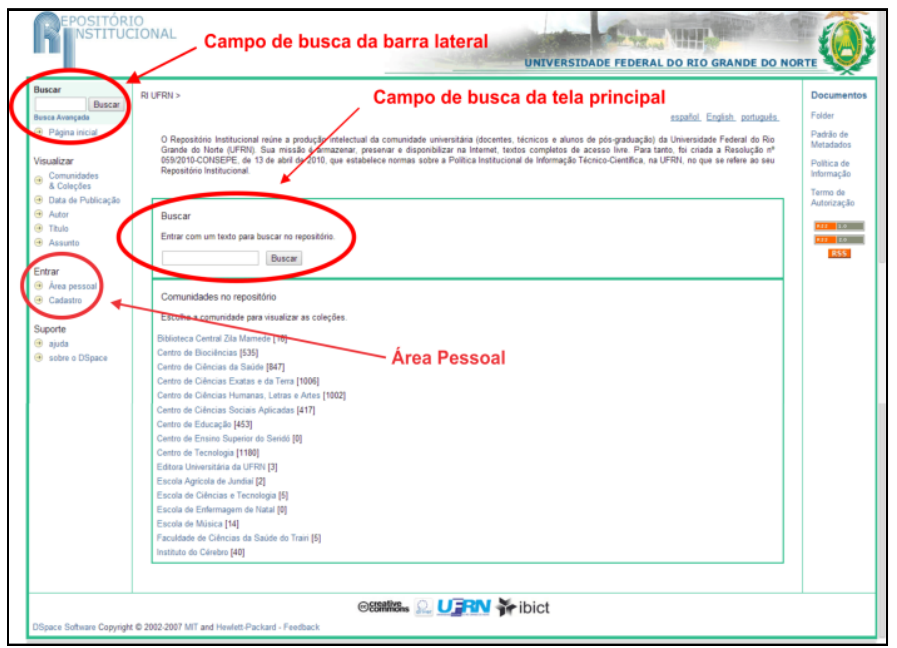

Figura 3- Página principal do RI-UFRN e campos de busca.

Fonte: Elaborada pelos autores, com base na pesquisa realizada.

Após realizar a busca de um documento, os usuários observaram que na página de resultados o campo "Pré-visualizar" não possui funcionalidade, tornando-se desnecessário e que a caixa de busca acima do resultado (Figura 4) precisaria ser apresentada com destaque mais acentuado.

\section{Voz do Usuário:}

"Como temos alunos com dificuldades de visão, achei que a fonte está muito pequena."

Busca: Em todo repositório

$$
\text { para O regime da memória : Buscar }
$$

Figura 4 - Caixa de busca da página de resultados.

Fonte: Elaborada pelos autores, com base na pesquisa realizada.

Ao selecionar um dos documentos da lista de resultados, o sistema apresenta uma tela com as principais informações do documento. Na opinião dos usuários, nesta tela, o campo "URI" (Figura 5) induz a pensar que o link leva ao documento e que, tal campo torna-se desnecessário, pois aponta para a mesma página que está sendo visualizada. Ainda apontam que o link para o documento (Figura 6) deveria estar destacado e posicionado próximo ao título, e que a informação, "Tamanho", do arquivo é desnecessária.

URI: http///repositorio ufrn.br:8080/jspui/handle/1/8411

Figura 5 - Campo URI.

Fonte: Elaborada pelos autores, com base na pesquisa realizada.

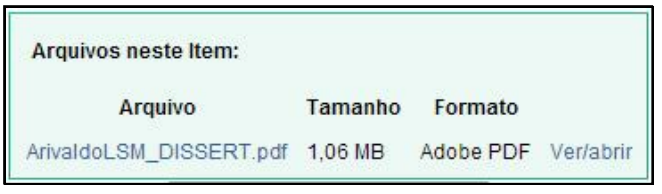

Figura 6 - Caixa com link para o documento.

Fonte: Elaborada pelos autores, com base na pesquisa realizada. 
Ao clicar no botão "Apresentar o registro completo", o sistema apresenta informações em código de programação. Sobre este ponto, os usuários acreditam que não faz sentido existir este tipo de apresentação do documento, pois gera confusão e duplicidade de informação. Os usuários observaram também que o botão "View Statistics" está apresentado em inglês.

\section{Voz do Usuário:}

"Não dá para entender o que o sistema diz. Parecem códigos, não sei. Não faz sentido, se o resultado já tinha sido apresentado."

\subsubsection{Tarefa 2: submissão de um documento}

Ao iniciar a submissão de um documento, os usuários precisam ter um cadastro no sistema e autenticarem-se na "Área pessoal" (Figura 3) com seus dados. Sobre o botão "Área Pessoal", os usuários apontaram que a nomenclatura utilizada não permite o entendimento de que esta é a área de submissão.

\section{Voz do Usuário:}

"Para submeter deveria ter alguma chamada na página principal. Eu tenho que entrar na 'Área Pessoal' para ver se tem a opção."

Na tela de autenticação (Figura 7) apontaram que as caixas de endereço de $e$ mail e senha estão distantes do link "Esqueceu a senha?", chegando a ser despercebida esta opção.

\section{Voz do Usuário:}

"O link 'Esqueceu a senha?' está no canto inferior esquerdo, quase não dá para perceber. Deveria estar próximo ao botão entrar."

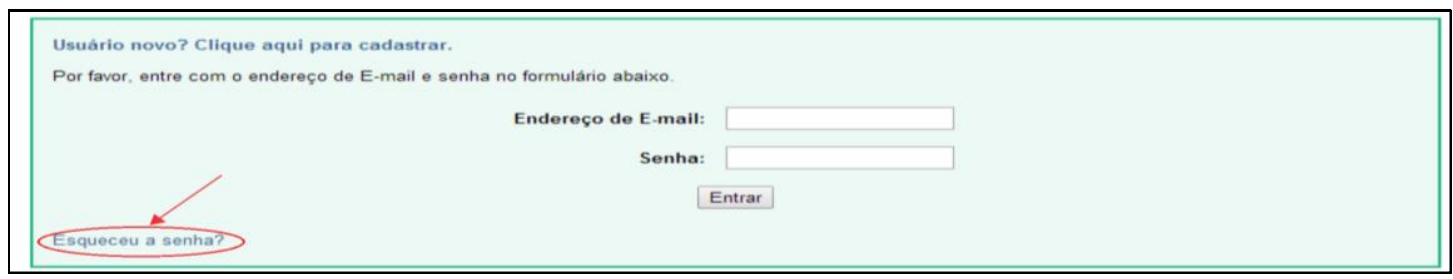

Figura 7 - Tela de autenticação.

Fonte: Elaborada pelos autores, com base na pesquisa realizada.

Após a autenticação o sistema remete os usuários para a área "Meu Espaço" (Figura 8), que permite iniciar uma nova submissão ou ver as submissões aceitas. Nesta etapa os usuários apontaram que a os botões estão distantes horizontalmente na tela.

Meu Espaço: Usuário 1 - Design

Iniciar uma nova submissão

Veja suas assinaturas

Fonte: Elaborada pelos autores, com base na pesquisa realizada. 
No primeiro passo da submissão o usuário deve selecionar, dentre as opções, a(s) que mais se adeque $(\mathrm{m})$ ao documento (Figura 9). Foi observado, pelos usuários, que os textos de instrução e das opções de seleção não são de fácil compreensão, e que a palavra "item", fosse substituída por documento.

\section{Voz do Usuário:}

"Horrivel esse português, não entendi."

"Acho que [palavra] cheque, não é muito comum, seria melhor: Por favor, marque o(s) campo(s) que se aplica(m) a essa submissão."

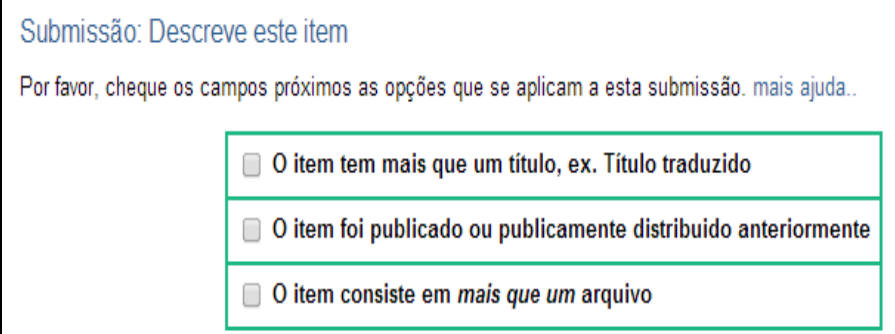

Figura 9 - Primeira etapa de descrição do documento.

Fonte: Elaborada pelos autores, com base na pesquisa realizada.

No segundo passo da submissão é apresentado o formulário para a descrição dos documentos. O Formulário atual é único para qualquer tipo de documento, e a indicação de quais campos são obrigatórios é exibida, somente, quando o usuário passa para a etapa seguinte. Nesta etapa, algumas observações foram feitas pelos usuários: a) o botão "Adicionar Mais" (Figura 10) deveria ser substituído pelo pictograma de adição e adicionar apenas um campo, ao invés de dois, por vez; b) falta de padronização, clareza e tamanho da fonte utilizada na apresentação das instruções de preenchimento dos campos; c) a data de publicação do documento deveria ser apresentada no formato dia-mês-ano; d) os campos do formulário, centralizados na tela causam desconforto; e) não houve entendimento quanto ao preenchimento do campo "Referência", levando os usuários a informarem todas as referências dos documentos usados para elaborar o trabalho; f) a caixa de seleção do "Tipo de Documento" (Figura 10) deveria ser apresentada no início do processo de submissão, personalizando, assim, o formulário por tipo de documento e; g) a nomenclatura do campo de seleção da língua do documento está apresentado em inglês "Language" (Figura 10).

\section{Voz do Usuário:}

"Eu removeria das instruções o texto 'em alguns programas browsers' e 'para salvar use o mouse'."

"Os campos obrigatórios deveriam ter destaque, não tem como saber."

"Isso [falta de indicação dos campos obrigatórios], me deixa extremamente chateado." 


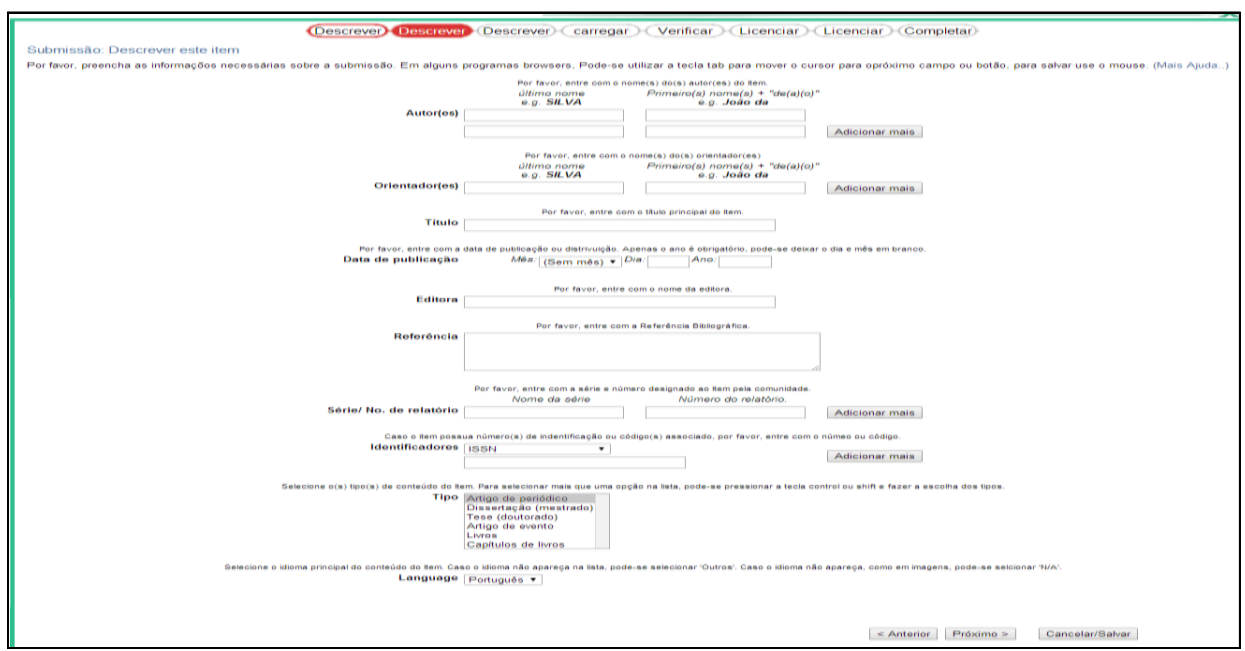

Figura 10 - Segunda etapa de descrição do documento.

Fonte: Elaborada pelos autores, com base na pesquisa realizada.

O sistema do repositório apresenta um recurso que permite, ao usuário, identificar as etapas do processo de submissão (Figuras 10, 11, 12 e 13). Os usuários criticaram a repetição de nomenclatura de algumas etapas, além da falta de clareza no termo escolhido para descrever a etapa e falta de padronização da escrita.

\section{Voz do Usuário:}

"Talvez se estivessem mais distanciados, separados com seta, daria a impressão de fluxo."

"Não gostei do design, poderia ser apresentado em abas."

No terceiro passo da submissão (Figura 11), e ainda na etapa de descrever, são inseridas as últimas informações do documento. Sobre esta etapa os usuários apontaram: a) novamente a necessidade de alteração do botão "Adicionar Mais"; b) não entenderam a forma de preenchimento do campo "Palavras-chave"; c) sugeriram que a opção dos "Direitos de acesso" fosse apresentada antes de submeter o documento e; d) foi sugerido que o campo "Resumo" fosse apresentado em tamanho maior, mesmo havendo, atualmete, a possibilidade de manipular o tamanho.

\section{Voz do Usuário:}

"A caixa de texto de resumo deveria ser maior." 


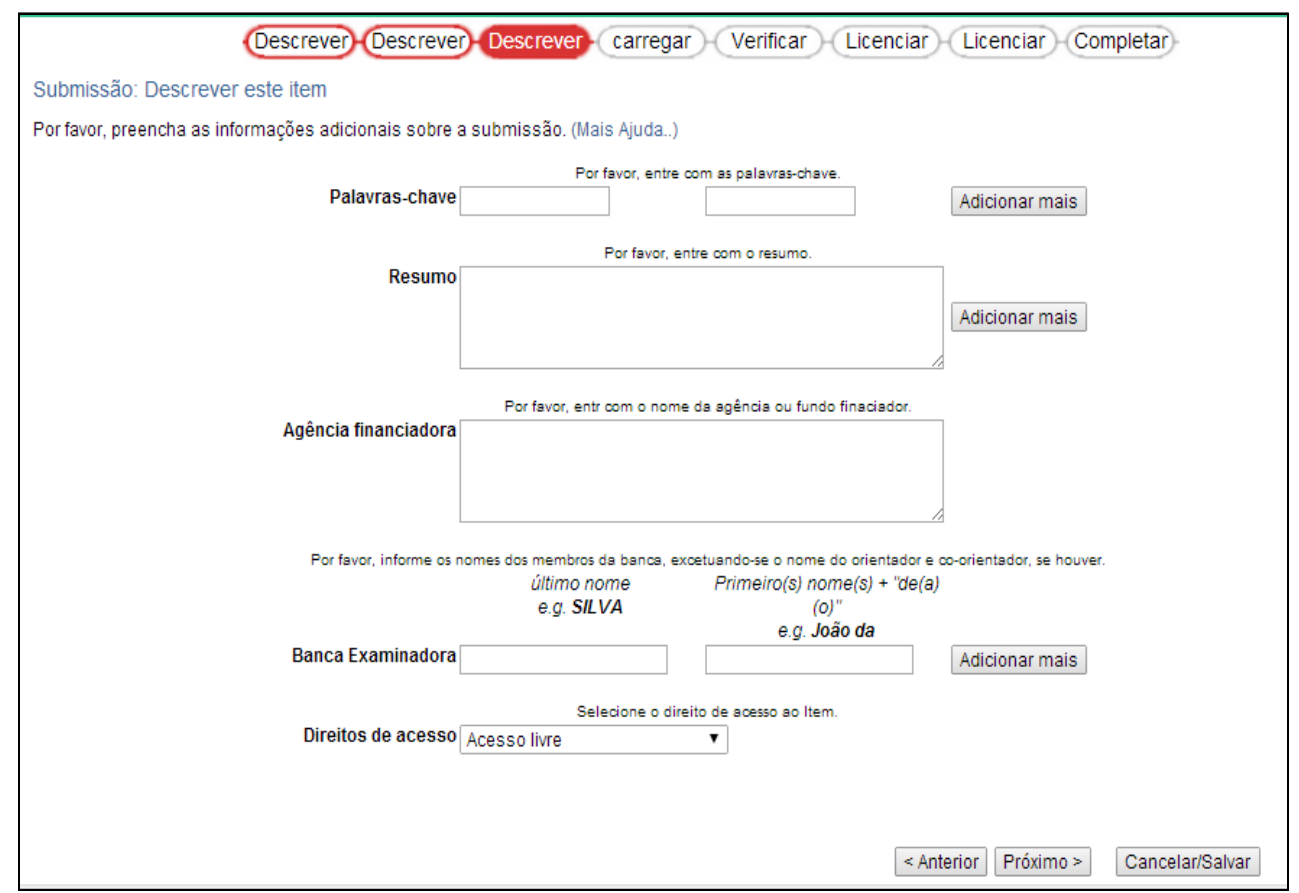

Figura 11 - Terceira etapa de descrição de um documento.

Fonte: Elaborada pelos autores, com base na pesquisa realizada.

A etapa "carregar" (Figuras 12 e 13) permite o usuário anexar e enviar o arquivo do documento que está sendo submetido, ao sistema. Após anexar o arquivo, o usuário deve clicar no botão "Próximo" para enviá-lo. Neste processo, o sistema não exibe informação sobre o progresso do carregamento do arquivo. Sobre esta etapa, os usuários apontaram que: a) não conseguiram identificar se o documento teria sido carregado; b) a mensagem de instrução pede para clicar em "Localizar", porém a nomenclatura do botão é "Escolher arquivo"; c) sentiram falta de um botão de envio; d) falta a informação que o arquivo só será enviado quando o usuário clicar em "Próximo"; e) o link que informa quais os formatos de arquivo que são aceitos, merece maior destaque e; f) não há necessidade da existência dos botões "Mostrar checksums", "Clique aqui se o formato estiver errado" e "Clique aqui se o arquivo estiver errado".

\section{Voz do Usuário:}

"Senti falta de uma mensagem dizendo se o documento foi carregado".

"Se eu não estivesse vendo aqui [informação do browser sobre o carregamento], eu ficaria clicando até agora."

"Deveria aparecer uma barra de progresso do carregamento do arquivo."

"O que é checksums?" [clicou no botão] "ai que loucura, para que isso? Parece nome de golpe de karatê" (Figura 13 e 14) [quando viu o resultado]. 


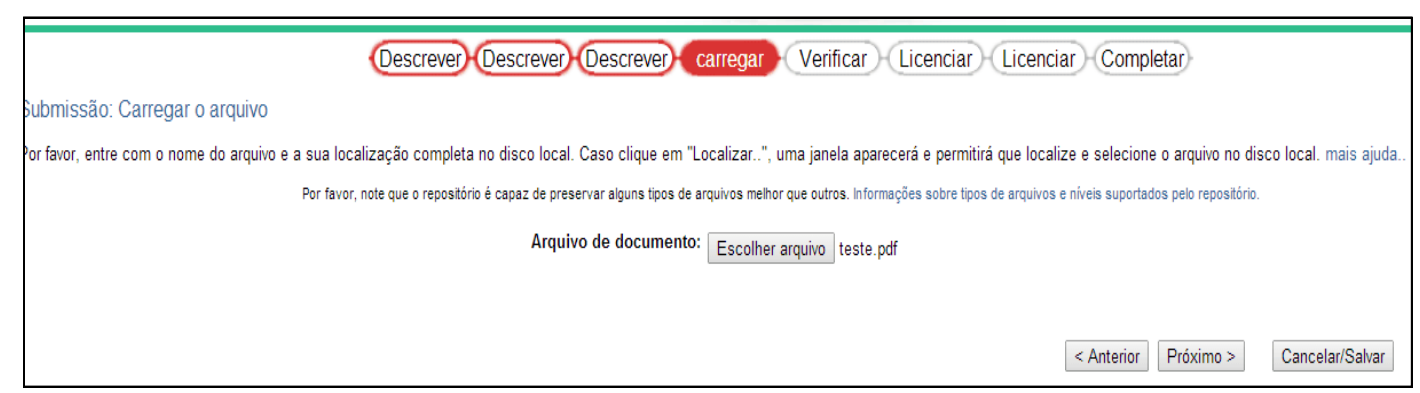

Figura 12 - Etapa de escolha do arquivo.

Fonte: Elaborada pelos autores, com base na pesquisa realizada.

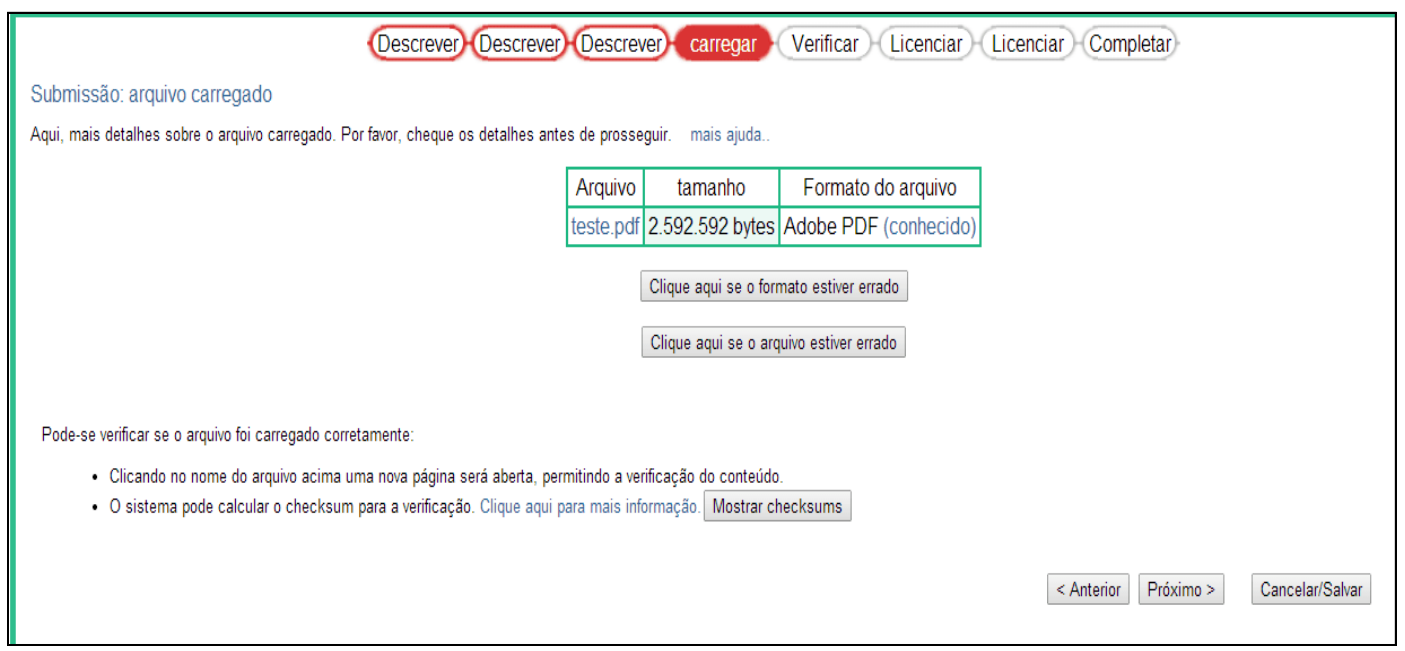

Figura 13 - Etapa de confirmação do arquivo anexado.

Fonte: Elaborada pelos autores, com base na pesquisa realizada.

\begin{tabular}{|c|c|c|c|}
\hline Arquivo & tamanho & Formato do arquivo & Checksum \\
\hline Lista de Presença 10-03-ufrn.pdf & 106-184 bytes & Adobe PDF (conhecido) & 36d3a3edf1d3e0320427e96751ea0d28 (MD5) \\
\hline
\end{tabular}

Figura 14 - Resultado de Checksums.

Fonte: Elaborada pelos autores, com base na pesquisa realizada.

Na etapa "Verificar", o usuário pode visualizar as informações preenchidas e corrigí-las caso seja necessário. Os participantes da avaliação, sugeriram a alteração da nomenclatura do botão "Corrigir um destes" por "Editar" e, também, mostraram-se insatisfeitos pelo sistema não retornar, automaticamente, para o passo "Verificar", após a correção da informação.

\section{Voz do Usuário:}

"O ideal seria corrigir [a informação] nesta mesma etapa".

"Eu achava que ia retornar para a tela que estava. Eu vou ter que passar tudo de novo."

As duas etapas seguintes tratam dos direitos autorais. A primeira disponibiliza a licença Creative Commons, que é desconhecida pelos participantes da avaliação. Apontaram também, que o texto com as informações sobre as licenças precisa de maior destaque. A nomenclatura do botão "Escolha uma licença" causou confusão, pois não foi percebido que este botão levaria à confirmação da autorização da licença. O outro motivo de confusão, nesta etapa, foi o botão "Pular Creative Commons", pois não houve compreensão imediata de que a licença Creative Commos não é obrigatória. 
Sobre a segunda licença, os usuários apontaram que o texto na língua inglesa não permite a compreensão da informação levando à desistência da submissão. Outra observação dos usuários foi que, todas as opções que tratam de permissões e licenças, deveriam ser apresentadas no início da submissão.

A avaliação realizada no RI-UFRN corrobora com Santa Rosa e Moraes (2012b), quando afirmam que o problema principal dos websites é que, ao não encontrarem o que precisam, as pessoas acabam desistindo da tarefa. "Há muitos casos em que isso acontece não apenas por problemas de usabilidade, mas por falhas em sua arquitetura da informação".

Voz do Usuário:

"O botão 'Escolha uma licença' está confuso, deveria ser 'Concordo' e 'Discordo'."

"Aqui [opções da licença Creative Commos] eu marco o que?"

"Essa licença em inglês fica parecendo que as pessoas que criaram [o repositório] estavam com muito cuidado no início e depois cansaram."

O repositório possui uma página de ajuda, que pode ser acessada pelos usuários em caso de dúvidas. Durante a avaliação este recurso foi considerado sem utilidade, pois é apresentado na língua inglesa.

\section{Voz do Usuário:}

"É totalmente inútil, pois está em inglês. Deveriam embutir as informações de ajuda no layout."

"A ajuda em inglês não ajuda. Se eu precisasse tirar alguma dúvida acabaria desistindo da submissão."

A última tela do processo de submissão apresenta a mensagem de confirmação da submissão, a opção para iniciar um novo processo e outros links. Os participantes da avaliação apontaram que: a) a mensagem de confirmação merece maior destaque; b) os botões "Ir para Meu espaço" e "Comunidades e Coleções" confundem-se com a tipografia da mensagem "Submissão: Submissão completa", levando ao entendimento de que todos são hiperlinks e; c) identificaram também que o botão para iniciar uma nova submissão está em inglês.

\section{Voz do Usuário:}

"Já acabou? Esta mensagem [Submissão completa] precisa ser mais destacada."

"Horrível! Eu não consigo perceber que isso aqui [links 'Ir para Meu Espaço' e 'Comunidades e Coleções'] é um link."

"O botão 'Submit another item to the same collection' deveria estar em português".

\section{CONCLUSÃO}

A partir da avaliação realizada constatou-se que os problemas de usabilidade e arquitetura da informação presentes no sistema do Repositório Institucional, geraram insatisfação nos usuários pesquisados e podem comprometer a percepção destes a respeito da confiabilidade, tais como: rotulagem, tamanho da fonte, nomenclatura dos botões. Acredita-se que o redesign da interface do Repositório Institucional da UFRN, 
que considere os aspectos de usabilidade e de arquitetura da informação, supracitados, contribuirá para melhoria do acesso e visibilidade de informações (KOSHIYAMA; CARVALHO; RAMOS, 2011) - passando a promover, de acordo com Santa Rosa (2009), uma abordagem centrada no leitor.

Enfatizamos a importância da realização de avaliações em outros aspectos do repositório, sob a ótica da usabilidade e da arquitetura da informação, de modo a propor recomendações a respeito de áreas específicas do sistema e a obter resultados mais conclusivos.

\section{REFERÊNCIAS}

ARELLANO, Miguel Angel. Preservação de documentos digitais. Ci. Inf., Brasília, v. 33, n. 2, p. 15-27, maio/ago. 2004. Disponível em:

<http://www.scielo.br/pdf/ci/v33n2/a02v33n2.pdf>. Acesso em: 15 mar. 2014.

ASSOCIAÇÃO BRASILEIRA DE NORMAS TECNICAS - ABNT. NBR 9241-11: Requisitos

Ergonômicos para Trabalho de Escritórios com Computadores Parte 11 - Orientações sobre Usabilidade, 2002. Disponível em:

<http://www.inf.ufsc.br/ cybis/pg2003/iso9241-11F2.pdf>. Acesso em: 12 out. 2013.

GIL, Antonio Carlos. Métodos e técnicas de pesquisa social. São Paulo: Atlas, 1999.

INSTITUTO BRASILEIRO DE INFORMAÇÃO EM CIÊNCIA E TECNOLOGIA - IBICT. Edital de chamada FINEP/PCAL/XBDB № 001/2009. Brasília, 2009. Disponível em:

<http://www.ibict.br/anexos_noticias/EDITAL_distrib_epto_pcal_xbdb_2_2009.doc >. Acesso em: 15 mar. 2014.

KOSHIYAMA, Débora Araújo; CARVALHO, Maria de Fátima de; RAMOS, Anatália Saraiva Martins. Implantação de repositório digital em universidade: relato de duas experiências na UFRN. Natal, 2011. 30f. Artigo (Especialização). Universidade Federal do Rio Grande do Norte. Especialização em Gestão Universitária.

LEITE, Fernando César Lima; COSTA, Sely. Repositórios institucionais como ferramentas de gestão do conhecimento científico no ambiente acadêmico. Perspect. Ciênc. Inf., Belo Horizonte, v. 11, n. 2, p.206-219, 2006. Disponível em:

<http://www.scielo.br/pdf/\%0D/pci/v11n2/v11n2a05.pdf>. Acesso em: 15 mar. 2014.

NIELSEN, Jakob. Usability Engineering. Montview: Sunsoft, 1993.

MONK, Andrew; WRIGHT, Peter; HABER, Jeanne; Davenport, Lora. Improving your human-computer interface: A practical technique. Prentice Hall International: UK, 1993.

ROSENFELD, Louis; MORVILLE, Peter. Information architecture for the World Wide Web. 3.ed. Sebastopol: O’Reilly, 2006.

RODRIGUES, Eloy et al. RepositóriUM: criação e desenvolvimento do Repositório Institucional da Universidade do Minho. Disponível em: 
<http://repositorium.sdum.uminho.pt/bitstream/1822/422/1/BAD_artigo\%20\%20Final.pdf>. Acesso em: 15 mar. 2014.

SANTA ROSA, José Guilherme. Em rumo ao paradigma Biblioteca Centrada no Leitor. In: Congresso Internacional de Usabilidade de Interfaces Humano-Computador, 9. 2009, Curitiba. Anais...Curitiba: UFPR, 2009. p.1-6.

SANTA ROSA, José Guilherme; MORAES, Anamaria de. Avaliação e projeto no design de interfaces. 2. Ed. Teresópolis, RJ: 2AB, 2012a.

Design Participativo. Rio de Janeiro, RJ: Rio Book's, 2012b.

UNIVERSIDADE Federal do Rio Grande do Norte. Repositório Institucional. Disponível em: < http://repositorio.ufrn.br:8080/jspui/>. Acesso em: 21 mar. 2014.

VIANA, Cassandra.L.M.; MÁRDERO ARELLANO, Miguel.A.; SHINTAKU, Milton.

Repositórios institucionais em ciência e tecnologia: uma experiência de customização do DSpace. Disponível em:

<http://eprints.rclis.org/bitstream/10760/7168/1/viana358.pdf>. Acesso em: 23 mar. 2014. 